\title{
Bispecific antibody-activated T cells enhance NK cell-mediated antibody-dependent cellular cytotoxicity
}

Zhaoming Wang ${ }^{1,2}$, Chaobo Yin ${ }^{1,3}$, Lawrence G. Lum ${ }^{4}$, Andrean Simons ${ }^{1,2,5}$ and George J. Weiner ${ }^{1,2,3^{*}}$ (])

\begin{abstract}
Resistance to anti-cancer monoclonal antibody $(\mathrm{mAb})$ therapy remains a clinical challenge. Previous work in our laboratory has shown that T cell help in the form of interleukin-2 maintains long-term NK cell viability and NK cellmediated antibody-dependent cellular cytotoxicity (ADCC). Lack of such T cell help may be a potential mechanism for resistance to $\mathrm{mAb}$ therapy. Here, we evaluate whether concomitant treatment with anti-CD3 $\times$ anti-cancer bispecific antibodies (bsAbs) can overcome this resistance by enhancing T cell help, and thereby maintaining long-term NK cell-mediated ADCC. Normal donor peripheral blood mononuclear cells were depleted of T cells, replenished with defined numbers of autologous T cells (from 0.75 to 50\%) and co-cultured with mono-/bispecific antibody-treated target tumor cells for up to 7 days. At low T cell concentrations, bsAb-activated T cells (mainly CD4 ${ }^{+} \mathrm{T}$ cells) were more effective than resting T cells at maintaining NK cell viability and ADCC. Brief ( $4 \mathrm{~h}$ to 2 day) bsAb exposure was sufficient to enhance long-term ADCC by NK cells. These findings raise the hypothesis that local T cell activation mediated by systemic treatment with anti-CD3 $X$ anti-cancer bsAb may enhance the anti-tumor efficacy of monospecific mAbs that mediate their primary therapeutic effect via NK-mediated ADCC.
\end{abstract}

Keywords: NK cell, ADCC, Anti-CD20, Blinatumomab, Bispecific antibody

\section{To the editor,}

Anti-cancer monoclonal antibodies (mAbs), including rituximab (anti-CD20) and cetuximab (anti-EGFR), are a standard component of cancer therapy. A major mechanism of action of anti-cancer mAbs is NK cell-mediated antibody-dependent cellular cytotoxicity (ADCC) [1, 2]. Resistance to $\mathrm{mAb}$ therapy remains a clinical challenge. Our previous work suggests that $\mathrm{T}$ cell help, mediated largely by interleukin-2 (IL-2) locally produced by $\mathrm{CD} 4^{+}$ $\mathrm{T}$ cells, maintains long-term NK cell-mediated ADCC and NK number [3]. Thus, lack of adequate $\mathrm{T}$ cell help may explain some cases of resistance to mAb therapy.

*Correspondence: george-weiner@uiowa.edu

${ }^{1}$ Holden Comprehensive Cancer Center, University of lowa, 5970-Z JPP, 200 Hawkins Drive, lowa City, IA 52242, USA

Full list of author information is available at the end of the article
IL-2 is well known to enhance NK cell activation and ADCC [4, 5]. However, systemic IL-2 administration results in significant toxicity and non-selectively expands regulatory $T$ cells $[6,7]$, thereby lessening enthusiasm for such combinations. Anti-CD3 x anti-cancer bispecific antibodies (bsAbs) redirect $\mathrm{T}$ cell cytotoxicity towards tumor cells [8]. bsAb-activated T cells also produce proinflammatory cytokines, including IL-2 [9, 10]. Here, we explore the hypothesis that bsAb can induce the local production of IL- 2 by T cells and maintain NK cell-mediated ADCC.

$\mathrm{T}$ cells were depleted from peripheral blood mononuclear cells (PBMCs) and autologous $\mathrm{T}$ cells were added back in known concentrations along with target Raji cells, rituximab (RTX) and blinatumomab (anti-CD19 $\mathrm{X}$ anti-CD3) and cultured for 1 week (Additional file 2). Blinatumomab at either 1 or $10 \mathrm{ng} / \mathrm{mL}$ [11] enhanced 
elimination of Raji cells by RTX-activated NK cells (Fig. 1A) and increased the number of viable NK cells (Fig. 1B), particularly when lower numbers of $\mathrm{T}$ cells were present. By contrast, RTX or blinatumomab alone had minimal impact on NK cells or ADCC when small numbers of $\mathrm{T}$ cells were present. The addition of $\mathrm{T}$ cells in the trastuzumab control group had little effect on $\mathrm{CD} 19^{+}$cell numbers indicating nutrient depletion was not responsible for limiting Raji growth. These results demonstrate that small numbers of $\mathrm{T}$ cells activated by blinatumomab enhance RTX-mediated ADCC and NK cell number. The number of viable NK cells was lower in response to RTX plus blinatumomab compared to RTX alone at high T cell concentrations, likely due to the early elimination of target cells and the loss of the RTX-mediated activating signal to NK cells. Concentrations of blinatumomab below $1 \mathrm{ng} / \mathrm{ml}$ had limited impact on RTX-mediated NK cell responses (Fig. 1C, D). Similar results were observed with Daudi cells serving as target cells (Additional file 1: Figure S1). Both $\mathrm{CD}^{+}{ }^{+}$and $\mathrm{CD} 8^{+} \mathrm{T}$ cells were able to produce IL-2 in response to blinatumomab (Additional file 1: Figure
S2). Blinatumomab-activated $\mathrm{CD} 4^{+}$and $\mathrm{CD}^{+} \mathrm{T}$ cells enhanced NK cell ADCC and number, with $\mathrm{CD} 4^{+} \mathrm{T}$ cells being more effective at low $\mathrm{T}$ cell concentrations (Additional file 1: Figure S3).

One major challenge associated with the clinical use of blinatumomab is the need for a continuous 28-day infusion. This led to evaluation of whether short-term blinatumomab exposure can provide enough $\mathrm{T}$ help to support RTX-mediated NK cell ADCC. Blinatumomab was added to the culture for various periods of time, then washed out while RTX was maintained for the full 7 days (Fig. 2A). Short-term (4-h or 2-day) blinatumomab exposure enhanced NK cell ADCC and number (Fig. 2B, C). A similar IL-2 washout experiment (Fig. 2D) was performed to explore the role of IL-2 in this process. These results (Fig. 2E, F) are consistent with our prior observation that IL-2 production by $\mathrm{T}$ cells is central to providing help for NK-mediated ADCC. Additionally, EGFRBi (anti-EGFR X anti-CD3) [12] enhanced cetuximab-mediated NK cell ADCC, suggesting bsAb-induced T cell help can enhance ADCC mediated by mAb against other targets (Additional file 1: Figure S4).

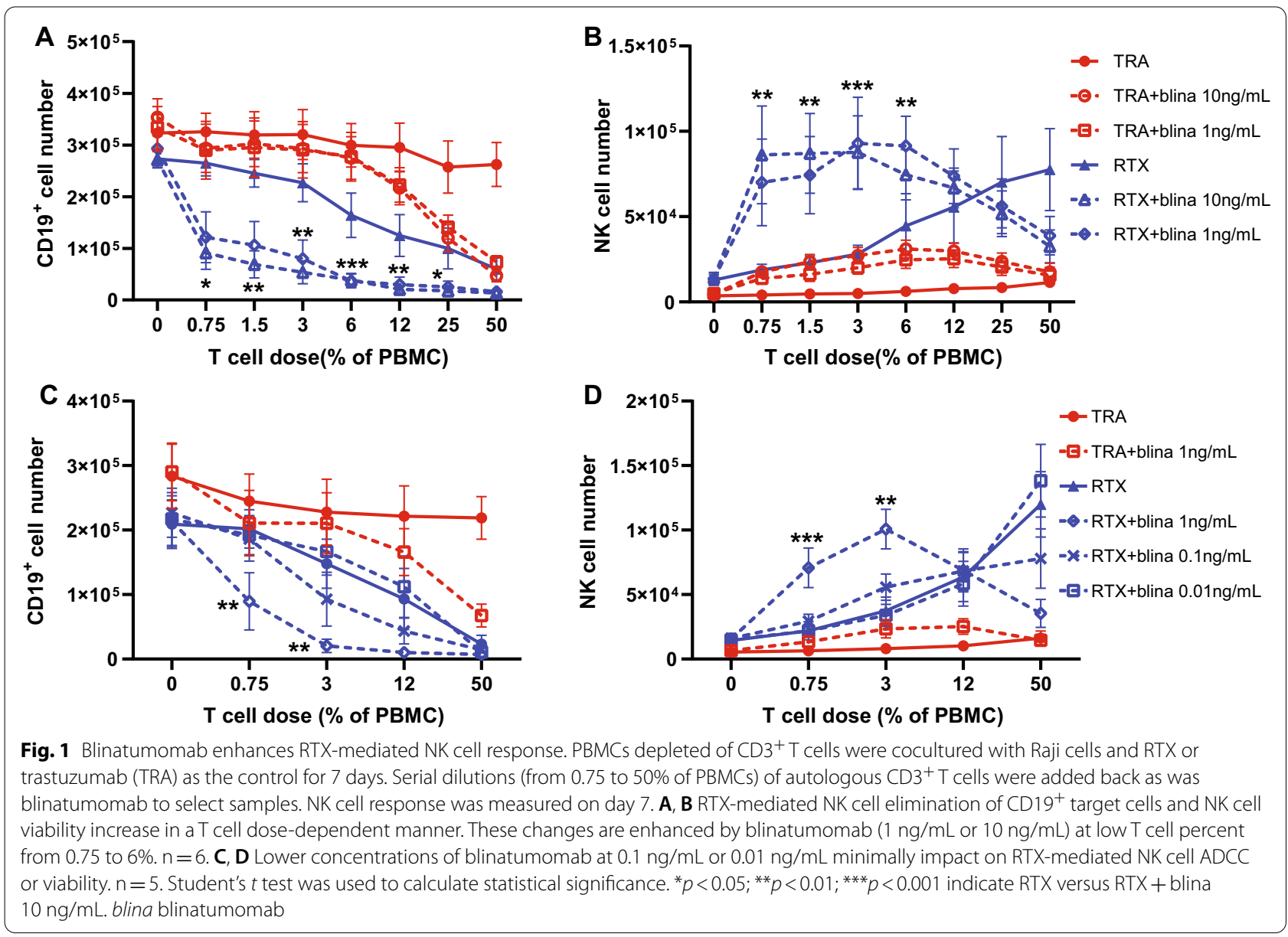




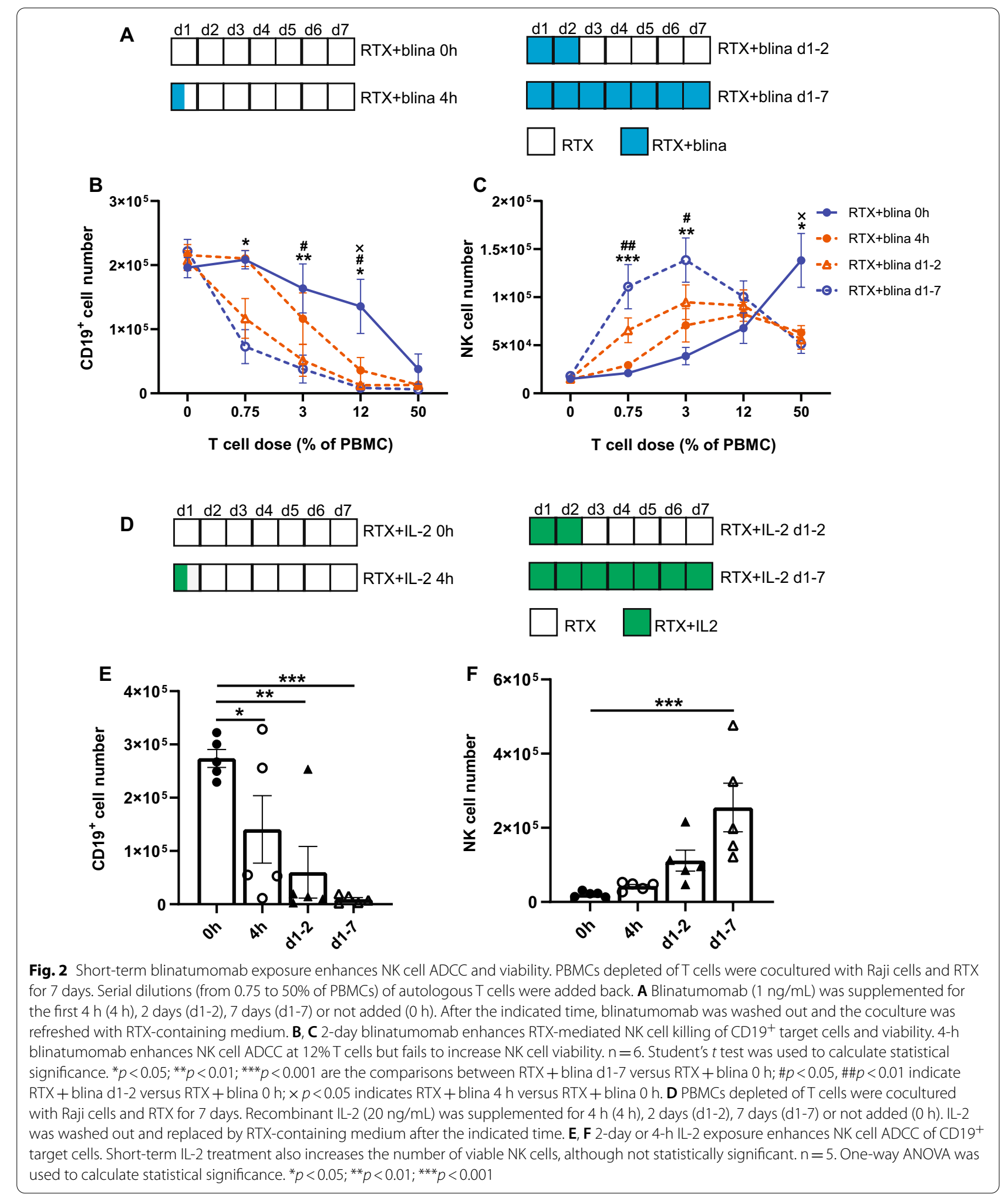


Collectively, these studies describe a novel mechanism of interaction between mAbs and bsAbs that has the potential to enhance the therapeutic effectiveness of both agents. Anti-CD3 $\times$ anti-cancer bsAb induces the local production of cytokines, including IL-2 by $\mathrm{T}$ cells which, in turn, enhances NK cell viability and ability to mediate ADCC. It is important to note that PBMCs are an imperfect surrogate for the tumor microenvironment. We considered evaluating this hypothesis in animal models however pilot studies demonstrated significant differences between the human and murine systems. Thus, evaluation of the underlying hypothesis of this manuscript in murine models would be of limited value. A clinical trial is expected to open shortly to further test the hypothesis that intratumoral $\mathrm{T}$ cell activation by shortterm systemic bsAb treatment could enhance the efficacy of anti-tumor mAb where NK-mediated ADCC is a primary mechanism of action (Additional file 2).

\section{Abbreviations \\ ADCC: Antibody-dependent cellular cytotoxicity; bsAb: Bispecific antibody; CTX: Cetuximab; IL-2: Interleukin 2; mAb: Monoclonal antibody; PBMC: Periph- eral blood mononuclear cell; RTX: Rituximab; TME: Tumor microenvironment; TRA: Trastuzumab.}

\section{Supplementary Information}

The online version contains supplementary material available at https://doi. org/10.1186/s13045-021-01216-w.

Additional file 1. Supplementary Figures. Figure S1. Blinatumomab enhances RTX-mediated NK cell response in Daudi cells. Figure S2. CD4+ and CD8 $+\mathrm{T}$ cells produce $\mathrm{IL}-2$ in response to blinatumomab. Figure S3. CD4+ is more efficient than CD8+ T cells in providing help to enhance RTX-mediated NK cell response. Figure S4. EGFRBi enhances cetuximabmediated NK cell response.

Additional file 2. Materials and Methods.

\section{Acknowledgements}

L.G.L is co-founder of Transtarget, Inc and serves on the SAB of RAPA Therapeutics.

\section{Authors' contributions}

Z.M.W performed experiments, analyzed the data and wrote the manuscript; C.B.Y performed experiments; L.G.L and A.S wrote the manuscript; G.J.W generated the concept, designed the research, analyzed the data and wrote the manuscript. All authors read and approved the final manuscript.

\section{Funding}

This work was supported by NCI P50CA97274 (G.J.W) and P30 CA86862 (G.J.W). L.G.L was supported in part by NIH/NCI R01CA182526.

\section{Availability of data and materials}

All data are available on reasonable request.

\section{Declarations}

\section{Ethical approval and consent to participate}

The use of human samples was approved by the Institutional Review Board at the University of lowa.
Consent for publication

Not applicable.

\section{Competing interests}

Not declared.

\section{Author details}

${ }^{1}$ Holden Comprehensive Cancer Center, University of lowa, 5970-Z JPP, 200 Hawkins Drive, lowa City, IA 52242, USA. ${ }^{2}$ Cancer Biology Graduate Program, University of lowa, lowa City, IA, USA. ${ }^{3}$ Department of Internal Medicine, University of lowa, lowa City, IA, USA. ${ }^{4}$ Division of Hematology/Oncology, Department of Medicine, The University of Virginia, Charlottesville, VA, USA.

${ }^{5}$ Department of Pathology, University of lowa, lowa City, IA, USA.

Received: 27 September 2021 Accepted: 25 November 2021

Published online: 09 December 2021

\section{References}

1. Weiner GJ. Rituximab: mechanism of action. Semin Hematol. 2010;47:115-23. https://doi.org/10.1053/j.seminhematol.2010.01.011.

2. Weiner GJ. Building better monoclonal antibody-based therapeutics. Nat Rev Cancer. 2015:15:361-70. https://doi.org/10.1038/nrc3930.

3. Wang Z, Chimenti MS, Strouse C, Weiner GJ.T cells, particularly activated CD4(+) cells, maintain anti-CD20-mediated NK cell viability and antibody dependent cellular cytotoxicity. Cancer Immunol Immunother. 2021. https://doi.org/10.1007/s00262-021-02976-7.

4. Golay J, et al. Rituximab-mediated antibody-dependent cellular cytotoxicity against neoplastic B cells is stimulated strongly by interleukin-2. Haematologica. 2003:88:1002-12.

5. Eisenbeis CF, et al. Combination immunotherapy of B-cell non-Hodgkin's lymphoma with rituximab and interleukin-2: a preclinical and phase I study. Clin Cancer Res. 2004;10:6101-10. https://doi.org/10.1158/10780432.CCR-04-0525.

6. Trotta R, et al. TGF-beta utilizes SMAD3 to inhibit CD16-mediated IFNgamma production and antibody-dependent cellular cytotoxicity in human NK cells. J Immunol. 2008;181:3784-92. https://doi.org/10.4049/ jimmunol.181.6.3784.

7. Khan KD, et al. A phase 2 study of rituximab in combination with recombinant interleukin-2 for rituximab-refractory indolent non-Hodgkin's Iymphoma. Clin Cancer Res. 2006;12:7046-53. https://doi.org/10.1158/ 1078-0432.CCR-06-1571.

8. Krishnamurthy A, Jimeno A. Bispecific antibodies for cancer therapy: a review. Pharmacol Ther. 2018;185:122-34. https://doi.org/10.1016/j. pharmthera.2017.12.002.

9. Rogala B, et al. Blinatumomab: enlisting serial killer T-cells in the war against hematologic malignancies. Expert Opin Biol Ther. 2015;15:895908. https://doi.org/10.1517/14712598.2015.1041912.

10. Wooldridge JE, Dahle CE, Weiner GJ. T-cell activation induced by antiCD3 $\times$ anti-B-cell lymphoma monoclonal antibody is enhanced by pretreatment of lymphoma cells with soluble CD40 ligand. Cancer Immunol Immunother. 1997:45:174-9. https://doi.org/10.1007/s002620050426.

11. Loffler $A$, et al. A recombinant bispecific single-chain antibody, CD19 x CD3, induces rapid and high lymphoma-directed cytotoxicity by unstimulated T lymphocytes. Blood. 2000;95:2098-103.

12. Lum LG, et al. Clinical and immune responses to anti-CD3 $\times$ anti-EGFR bispecific antibody armed activated T cells (EGFR BATs) in pancreatic cancer patients. Oncoimmunology. 2020;9:1773201. https://doi.org/10. 1080/2162402X.2020.1773201.

\section{Publisher's Note}

Springer Nature remains neutral with regard to jurisdictional claims in published maps and institutional affiliations. 